\title{
A phase I/II, non-randomized, feasibility/safety and efficacy study of the combination of everolimus, cetuximab and capecitabine in patients with advanced pancreatic cancer
}

\author{
Sil Kordes • Dick J. Richel • Heinz-Josef Klümpen • \\ Mariëtte J. Weterman • Arnoldus J. W. M. Stevens • \\ Johanna W. Wilmink
}

Received: 3 January 2012 / Accepted: 9 February 2012 / Published online: 25 February 2012

(C) The Author(s) 2012. This article is published with open access at Springerlink.com

Summary Background Improvements in knowledge of molecular mechanisms in cancer are the basis for new studies combining chemotherapy with targeted drugs. Inhibition of the epidermal growth factor receptor (EGFR) by erlotinib or cetuximab has limited or no activity, respectively, in pancreatic cancer. The crosstalk between EGFR and mammalian target of rapamycin (mTOR) pathways is a potential mechanism of resistance; therefore we conducted a study to explore safety and efficacy of multiple pathway inhibition by cetuximab and everolimus in combination with capecitabine. Methods Safety and efficacy of fixed standard dose cetuximab in combination with various dose levels of everolimus (5-10 mg/day) and capecitabine (600-800 mg/ $\mathrm{m}^{2}$ bid, 2 weeks every 3 weeks) were investigated in a phase I/II study in patients with advanced pancreatic cancer. The primary endpoint was objective response. Results Sixteen patients were treated in the phase I part at two dose levels. Mucositis, rash and hand-foot syndrome were dose-limiting toxicities. Dose level 1 (everolimus $5 \mathrm{mg} /$ day, capecitabine $600 \mathrm{mg} / \mathrm{m}^{2}$ bid for 2 weeks every 3 weeks and cetuximab $250 \mathrm{mg} / \mathrm{m}^{2}$ weekly) was considered the maximum tolerated dose (MTD). Of 31 patients in the phase II part, partial response was documented in two patients $(6.5 \%)$ and five (16.1\%) had stable disease. Median overall survival was

S. Kordes $(\bowtie) \cdot$ D. J. Richel $\cdot$ H.-J. Klümpen • M. J. Weterman •

A. J. W. M. Stevens · J. W. Wilmink

Department of Medical Oncology,

Academic Medical Center Amsterdam,

Meibergdreef 9,

1105 AZ Amsterdam, The Netherlands

e-mail: s.kordes@amc.uva.nl
5.0 months (CI 3.1-6.8). Conclusion The schedule of capecitabine, everolimus and cetuximab resulted in considerable epidermal and mucosal toxicities and prevented escalation to optimal dose levels. Because of toxicity and low efficacy this treatment combination cannot be recommended for treatment in pancreatic cancer patients.

Keywords Pancreatic cancer Everolimus - Cetuximab . Capecitabine $\cdot$ Phase I $\cdot$ Phase II

\section{Introduction}

Pancreatic cancer patients have one of the worst prognoses among all cancer types with an overall survival rate of less than 5\% [1]. Since the publication of Burris in 1997 gemcitabine is still considered as the standard treatment for most patients with pancreatic cancer [2]. Several randomized clinical trials comparing gemcitabine in combination with other chemotherapeutic drugs have not resulted in survival improvement [3].

Moving away from the paradigm that combination therapy must be gemcitabine based, a strategy that has invariably failed, Conroy et al. recently demonstrated in a randomized clinical trial a significant survival advantage with the gemcitabine free combination chemotherapy regimen FOLFIRINOX as compared with gemcitabine [4]. Although patients were highly selected and toxicity was considerable, this trial opens the way to new treatment strategies in advanced pancreatic cancer. 
Significant improvements in our knowledge of the molecular mechanisms involved in cancer development and progression, and the availability of drugs interfering with aberrant activity in various signaling pathways, have subsequently resulted in numerous clinical trials combining conventional chemotherapy with various targeted drugs. The EGFR/ MAPK and PI3K/Akt/mTOR pathways are often dysregulated and considerable evidence supports the important role of these pathways in the biology of pancreatic cancer [5, 6]. Several targets in these pathways are potential candidates to achieve inhibition of aberrant signaling. Erlotinib, a tyrosine kinase EGFR inhibitor, was one of the first FDA approved tyrosine kinase inhibitors. In a randomized clinical trial in pancreatic cancer patients, erlotinib in combination with gemcitabine induced a statistically significant improvement in survival, although the two weeks survival benefit was considered clinically not meaningful [7]. Targeting EGFR with the monoclonal antibody cetuximab in combination with gemcitabine failed to demonstrate a survival advantage[8]. mTOR is an important signaling molecule in the PI3K pathway and inhibition of mTOR could inhibit tumor growth in pancreatic cancer xenograft models [9]. However, in a clinical study no benefit was demonstrated using the mTOR inhibitor everolimus as a single agent in second line [10]. Possible explanations for the relative insensitivity to drugs targeting only one aberrant molecule is the heterogeneous molecular pathogenesis of pancreatic cancer leading to deviant activation of multiple signaling pathways and the intensive crosstalk between these pathways $[11,12]$. Although some tumors with specific crucial mutations are sensitive to mono-targeted therapies, such as gastrointestinal stromal tumor and imatinib, for most cancer types including pancreatic cancer this is not the case $[13,14]$. Exploration of drug combinations targeting multiple pathways is therefore an interesting strategy to overcome drug resistance. Rational targets for this combined approach in pancreatic cancer are EGFR and mTOR, leading to synergistic anticancer activity as has been demonstrated in pre-clinical models [15-20].

Therefore we explored in the present study the feasibility and efficacy of a triple drug combination consisting of cetuximab, everolimus and capecitabine in patients with advanced pancreatic cancer. In an earlier phase I study we demonstrated that everolimus (10 mg daily) in combination with capecitabine $\left(1000 \mathrm{mg} / \mathrm{m}^{2}\right.$ BID) was a safe and tolerable regimen [21]. In the present study gemcitabine was replaced by capecitabine because gemcitabine in combination with everolimus induced severe bone-marrow toxicity already at the gemcitabine dose level of $600 \mathrm{mg} / \mathrm{m}$ [22]. The failure of gemcitabine based combination regimens was also taken in to account. The monoclonal antibody cetuximab instead of erlotinib was chosen because of potential pharmacokinetic interactions between erlotinib and mTOR inhibitors (at the level of cytochrome P (CYP) metabolizing enzymes) $[23,24]$.

\section{Patients and methods}

Study design and statistics

This multicenter open-label phase I/II trial consisted of two parts: the phase I part was traditionally designed with interpatient dose escalation in cohorts of three to six patients with the primary end point of protocol-defined dose limiting toxicity (DLT) and Maximum Tolerated Dose (MTD) [25]. The phase II part was designed to determinate the efficacy and feasibility of the combination of everolimus, capecitabine and cetuximab. Primary endpoint of this part of the study was response rate. Patients were defined as responders when a complete response (CR) or partial response (PR) by response evaluation criteria in solid tumors (RECIST) 1.0 was seen. Secondary endpoints were time to treatment failure (TTF), overall survival (OS), one-year survival rate and the toxicity profile according to NCI-CTC v3.0. TTF and OS were calculated by the Kaplan-Meier method, measured from the date of treatment initiation to the date of documented progression and death of any cause, respectively. All analyses were conducted on an intention-to-treat basis and were performed using SPSS version 18.0.2.

The phase II part was designed in two stages (Simon twostage optimal design) with an early stopping rule for efficacy: if no objective responses were to be observed within the first 14 patients treated at the MTD, the trial was to be halted, because this event $(0 / 14)$ has a probability of $<0.05$ if the true response rate is 0.20 .

The study was conducted according to the ethical principles of the Declaration of Helsinki and Good Clinical Practice and was approved by health authorities and the independent ethics committee of the Academic Medical Center Amsterdam. The trial is registered on the USA NCI Web site www.ClinicalTrials.gov (NCT01077986)

\section{Patients}

Patients with cytological or histological confirmed locally advanced or metastatic adenocarcinoma of the pancreas were eligible. Further inclusion criteria comprised an Eastern cooperative oncology group/World health organization (ECOG/WHO) performance status of 0,1 or 2, measurable lesions on $\mathrm{CT}$ according to RECIST 1.0 criteria (for the phase II part of the study), age eighteen years of age or older and a life-expectancy of at least three months. Patients had to be mentally, physically and geographically able to undergo treatment and follow-up. Adequate renal, liver and bone marrow function was necessary. Laboratory values accompanied hereby were serum creatinine $<150 \mu \mathrm{mol} / \mathrm{L}$, bilirubin $<1.5 \mathrm{x}$ upper limit of laboratory normal (ULN), aspartate aminotransferase and alanine aminotransferase $<2.5 \mathrm{x}$ 
ULN or $<5.0 \mathrm{x}$ in case of liver metastasis, white blood cell count $>3.0 \times 109$, platelets $>100 \times 109$, respectively.

Patients were not eligible if they had previous treatment with an mTOR inhibitor. Other exclusion criteria included pregnancy and lactation, clinical or radiological evidence of central nervous system metastasis at time of enrollment, known hypersensitivity to everolimus or other rapamycins or to its excipients, any severe and/ or uncontrolled medical conditions, such as clinically significant heart conditions or myocardial infarction in 6 months prior to randomization, uncontrolled diabetes as defined by fasting glucose above $1.5 \mathrm{x}$ ULN, active or uncontrolled infection, serious liver disease and severely impaired lung function, or a serious concomitant systemic disorder that would compromise the safety of the patient, at the discretion of the investigator. Written informed consent was obtained from each patient.

\section{Treatment}

Treatment was administered in a 3-week regimen consisting of continuous daily oral everolimus, weekly cetuximab, and capecitabine for 14 days followed by 7 days rest. For the phase I part, dose escalations were performed for everolimus and capecitabine, according to Table 1 . Cetuximab was given at a fixed dose of $250 \mathrm{mg} / \mathrm{m}^{2}$, with a start-up dose of $400 \mathrm{mg} / \mathrm{m}^{2}$.

If one of three patients experienced dose-limiting toxicity (DLT), three more patients were included at the same dose level. If two or more patients experienced DLT, the previous dose level was considered the MTD. All patients of the phase II part of the study were treated at the MTD.

DLTs were defined as any of the following adverse events as defined by the common terminology criteria for adverse events version 3.0 (CTCAE) in the first two cycles: grade 4 neutropenia lasting $>5$ days or febrile neutropenia grade 3 ; grade 4 thrombocytopenia and grade $\geq 3$ red cell count; grade $\geq 2$ vomiting and grade $\geq 3$ of any other toxicity despite supportive treatment, except rash, which was defined as DLT at grade 4.

In the phase II part, dose modifications were predefined for each drug. Everolimus dose was reduced in case of grade 3 toxicity or recurrence of grade 2 non-hematological toxicity or thrombocytopenia after interruption. Everolimus was

Table 1 Dose escalation levels phase I

\begin{tabular}{llll}
\hline Dose level & $\begin{array}{l}\text { Everolimus } \\
(\mathrm{mg})\end{array}$ & $\begin{array}{l}\text { Capecitabine } \\
\left(\mathrm{bid} \mathrm{mg} / \mathrm{m}^{2}\right)\end{array}$ & $\begin{array}{l}\text { Cetuximab } \\
(\mathrm{mg})\end{array}$ \\
\hline-1 & 5 & 400 & 250 \\
1 & 5 & 600 & 250 \\
2 & 10 & 600 & 250 \\
3 & 10 & 800 & 250 \\
\hline
\end{tabular}

bid twice daily

discontinued in case of grade 4 toxicity or recurrence of grade 3 hematological toxicity after dose reduction. Capecitabine had to be withheld in case of toxicity grade $\geq 2$ until recovery to grade $\leq 1$. Dose modifications were dependent on severity and frequency of toxicity, as defined in the protocol. Cetuximab had to be delayed for up to two consecutive infusions in case of grade $\geq 3$ skin toxicity whereas doxycyclin $100 \mathrm{mg}$ daily and local metronidazole treatment was initiated. The same dose level was restarted if toxicity resolved to grade $\leq$ 2 , with continuation of doxycyclin treatment. At second or third recurrence of grade 3 toxicity, dose was reduced to $200 \mathrm{mg} / \mathrm{m}^{2}$ and $150 \mathrm{mg} / \mathrm{m}^{2}$, respectively. Cetuximab was discontinued in case of withholding more than 2 infusions, fourth recurrence of skin toxicity grade $\geq 3$, or an allergic/ hypersensitivity reaction grade $\geq 3$. Treatment was continued until unacceptable toxicity, disease progression, withdrawal of informed consent by the patient or any other reason why continuation was not in the best interest of the patient. Response assessment by CT-scan (RECIST 1.0) was done at baseline and every 9 weeks during active treatment.

\section{Results}

Patients

In total 43 patients were enrolled between February 2009 and June 2010. Three patients were excluded from analysis because of major violation of the inclusion criteria; one

Table 2 Patient demographics and disease characteristics

WHO World Health Organization $D L$ Dose Level

${ }^{\text {a}}$ Phase II included 7 patients of the DL1 cohort and 24 patients of the phase II cohort

\begin{tabular}{|c|c|c|}
\hline Characteristic & $\begin{array}{l}\text { Phase } \text { II }^{\mathrm{a}} \\
\mathrm{N}=31 \\
(\%)\end{array}$ & $\begin{array}{l}\text { DL2 } \\
N=9 \\
(\%)\end{array}$ \\
\hline Median Age & 57.9 & 61 \\
\hline Range & $39-78$ & $45-69$ \\
\hline \multicolumn{3}{|l|}{ Gender } \\
\hline Male & $13(42)$ & $6(67)$ \\
\hline Female & $18(58)$ & $3(33)$ \\
\hline \multicolumn{3}{|c|}{ WHO performance status } \\
\hline 0 & $16(52)$ & $5(56)$ \\
\hline 1 & $10(32)$ & $3(33)$ \\
\hline 2 & $5(16)$ & $1(11)$ \\
\hline \multicolumn{3}{|l|}{ Stage of disease } \\
\hline $\begin{array}{l}\text { Locally } \\
\text { advanced }\end{array}$ & $4(13)$ & $1(11)$ \\
\hline Metastatic & $27(87)$ & $8(89)$ \\
\hline \multicolumn{3}{|c|}{ Localization of primary } \\
\hline Head & $23(74)$ & $8(89)$ \\
\hline Tail/corpus & $8(26)$ & $1(11)$ \\
\hline \multicolumn{3}{|l|}{ Line of therapy } \\
\hline First line & $22(71)$ & $6(67)$ \\
\hline$\geq$ Second line & $9(29)$ & $3(33)$ \\
\hline
\end{tabular}


Table 3 Dose interruptions and reductions

\begin{tabular}{llllll}
\hline & \multicolumn{2}{l}{ Interruptions } & & \multicolumn{2}{l}{ Reductions } \\
\cline { 2 - 3 } \cline { 5 - 6 } \cline { 5 - 6 } & Cycles (\%) & Patients (\%) & & Cycles (\%) & Patients (\%) \\
\hline Total DL2 & $10(40)$ & $5(56)$ & & $5(20)$ & $5(56)$ \\
Capecitabine & $5(20)$ & $4(44)$ & & $1(4)$ & $1(11)$ \\
Everolimus & $4(16)$ & $4(44)$ & & $4(16)$ & $4(44)$ \\
Cetuximab & $1(4)$ & $1(11)$ & & $0(0)$ & $0(0)$ \\
Total phase 2 & $22(20)$ & $8(26)$ & & $6(5)$ & $6(19)$ \\
Capecitabine & $6(5)$ & $3(10)$ & & $5(4)$ & $5(16)$ \\
Everolimus & $5(4)$ & $5(16)$ & & $1(1)$ & $1(3)$ \\
Cetuximab & $11(10)$ & $5(16)$ & & $0(0)$ & $0(0)$ \\
\hline
\end{tabular}

Total cycles: 25 in dose level 2 (DL2), 113 in phase 2. Total patients: 9 in DL2 and 31 in phase 2

patient in the phase I part of the study received eight cycles of treatment, while in retrospect no pancreatic cancer cells were seen in pathology. Two patients in the phase II part experienced rapid deterioration between signing informed consent and start of treatment.

Table 2 summarizes the baseline characteristics of all 40 eligible patients, separately for each dose level.

Phase I

Sixteen patients were enrolled in the phase I part of this study. Dose level I was expanded to six patients because 1 patient developed grade 3 mucositis as DLT. The same patient discontinued treatment because of cerebral infarction 6 weeks after start of treatment. Because of vascular
Table 5 Objective treatment response

\begin{tabular}{lll}
\hline Response & $N=31(\%)$ & CI \\
\hline PR & $2(6.5)$ & $1.1-18.8$ \\
SD & $5(16.1)$ & $6.2-31.2$ \\
PD & $17(54.8)$ & $37.9-71.1$ \\
Not assessed & $7(22.6)$ & $10.6-38.8$ \\
Objective Response rate $^{\mathrm{a}}$ & $2(6.5)$ & $1.1-18.8$ \\
Disease Control rate $^{\mathrm{b}}$ & $7(22.6)$ & $10.6-38.8$ \\
\hline
\end{tabular}

$P R$ partial response, $S D$ stable disease $P D$ progressive disease, $C I$ confidence interval ${ }^{\mathrm{a}}$ Objective response rate $=\mathrm{PR}{ }^{\mathrm{b}}$ Disease Control rate $=\mathrm{PR}+\mathrm{SD}$

problems in the medical history of the patient, this complication was considered not to be related to study medication. Nonetheless, we decided to include an additional patient in this dose level. In the first cohort of dose level II one patient developed grade 3 hand-foot syndrome as DLT. Therefore this dose level was expanded to six patients. One of those patients developed grade 3 hand-foot syndrome and mucositis. These were not considered to be DLTs, because by mistake one additional week of capecitabine was taken by the patient in the first cycle and symptoms resolved after 3 weeks of interruption and the original dose could be restarted. Because two other patients with progressive disease within the first cycle, were not assessable for toxicity, three additional patients were included in DL2. Subsequently one patient developed grade 4 rash and three patients had grade 3 mucositis as DLTs. Due to the five DLTs in DL2, DL1 was considered as the MTD and the recommended dose for the phase II part.
Table 4 Treatment related toxicity

$D L$ Dose Level ${ }^{\text {a }}$ Phase II includes 7 patients from DL1 and 24 from phase II

\begin{tabular}{|c|c|c|c|c|}
\hline & \multicolumn{2}{|c|}{31 patients in phase II analysis ${ }^{\mathrm{a}}$} & \multicolumn{2}{|c|}{9 patients in DL2 } \\
\hline & Any grade (\%) & Grade 3-4 (\%) & Any grade (\%) & Grade $3-4(\%)$ \\
\hline \multicolumn{5}{|l|}{ Hematologic } \\
\hline Anemia & $14(45)$ & $1(3)$ & $6(67)$ & $0(0)$ \\
\hline Neutropenia & $7(23)$ & $0(0)$ & $5(56)$ & $0(0)$ \\
\hline Thrombocytopenia & $8(26)$ & $0(0)$ & $3(33)$ & $0(0)$ \\
\hline \multicolumn{5}{|l|}{ Non hematological } \\
\hline Rash & $24(77)$ & $6(19)$ & $6(67)$ & $3(27)$ \\
\hline Mucositis & $14(45)$ & $4(13)$ & $6(67)$ & $4(36)$ \\
\hline Fatigue & $13(42)$ & $4(13)$ & $4(44)$ & $1(9)$ \\
\hline Diarrhea & $10(32)$ & $4(13)$ & $3(33)$ & $0(0)$ \\
\hline Hand-foot syndrome & $10(32)$ & $2(6)$ & $1(11)$ & $2(18)$ \\
\hline Infection & $5(16)$ & $1(3)$ & $2(22)$ & $2(18)$ \\
\hline Nausea/vomit & $16(52)$ & $1(3)$ & $6(67)$ & $0(0)$ \\
\hline Hypokalemia & $17(55)$ & $4(13)$ & $1(11)$ & $0(0)$ \\
\hline Hyperglycaemia & $19(61)$ & $8(26)$ & $5(56)$ & $1(18)$ \\
\hline Total unique patients & $31(100)$ & $23(74)$ & $9(100)$ & $8(89)$ \\
\hline
\end{tabular}




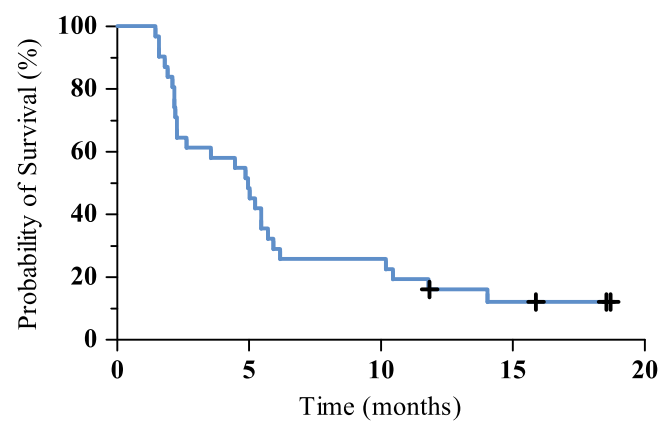

Fig. 1 Kaplan Meier curve of overall survival of all patients treated at the maximum tolerated dose. Median survival is 5.0 months (CI 3.1$6.8)+$ censored patients

In Table 4 all toxicity for the nine patients in dose level 2 is depicted. In these nine patients, a total of 25 complete cycles were given, with a median of 2 (range $0-10$ ) cycles per patient. Dose reductions and interruptions are depicted in Table 3.

Phase II

\section{Safety and toxicity}

In the phase II part of this study, 24 eligible patients were enrolled. When combined with the seven patients treated at MTD in the phase I part, a total of 31 patients could be evaluated according to the protocol. In these 31 patients, a total of 113 complete cycles were given, with a median (range) of $3.0(0-20)$ cycles per patient. Dose reductions and interruptions are depicted in Table 3 . Table 4 represents the treatment related toxicity. The most common grade 3/4 toxicities of the phase II part included hyperglycemia (26\%), rash $(19 \%)$, mucositis (13\%) and fatigue (13\%).

\section{Efficacy and survival}

Table 5 summarizes the objective response observed in the 31 treated patients (71\% first line, $29 \%$ second line) at the MTD level. Out of 31 patients, 24 patients were evaluable for response. Seven patients were not evaluable for response due to events before the first planned CT-evaluation: two patients were clinically progressive, one patient died (as described in the phase I part) and three patients stopped treatment because of treatment related toxicity (grade 3 diarrhea, intolerable rash). One patient refused further treatment. These seven patients were considered as nonresponders.

We observed two (6.5\% CI: $1.1-18.8 \%)$ partial responses according to RECIST 1.1. Five (16.1\% CI: 6.2-31.2\%) patients had stable disease, giving a disease control rate of $23.8 \%$. Seventeen (54.8\% CI: 37.9-71.1\%) patients had progressive disease.

Overall survival of the 31 patients treated at MTD was 5.0 months (CI 3.1-6.8 months) (Fig. 1). The one-year survival rate was $12,9 \%$. Time to treatment failure was 2.3 months (CI 1.7-2.8 months).

Table 6 summarizes overall survival differences between groups based on differences in baseline characteristics, measured by KM-method and a log-rank test. Overall survival for first line patients was 5.0 (CI 4.1-5.9) months, and for second line patients 3.6 months (CI 0.0-7.7) months, which was not a significant difference.
Table 6 Kaplan-Meyer analysis for overall survival, effect of baseline characteristics

WHO World Health Organization $C I$ Confidence Interval

\begin{tabular}{|c|c|c|c|c|c|}
\hline & Total & Censored & Median survival (Months, CI) & 1 year survival (\%) & Logrank_p \\
\hline All Patients & 31 & 4 & $5.0(3.1-6.8)$ & 12.9 & \\
\hline \multicolumn{6}{|l|}{ Sex } \\
\hline Female & 18 & 0 & $5.0(4.2-5.7)$ & 5.6 & \multirow[t]{2}{*}{0.203} \\
\hline Male & 13 & 4 & $4.5(1.7-7.3)$ & 23.1 & \\
\hline \multicolumn{6}{|l|}{ Age } \\
\hline$<65$ & 24 & 2 & $4.5(1.2-7.7)$ & 12.5 & \multirow[t]{2}{*}{0.112} \\
\hline$\geq 65$ & 7 & 2 & $10.2(0.0-20.5)$ & 14.3 & \\
\hline \multicolumn{6}{|c|}{ WHO performance status } \\
\hline 0 & 16 & 4 & $5.2(4.1-6.4)$ & 25.0 & \multirow[t]{3}{*}{0.093} \\
\hline 1 & 10 & 0 & $4.5(0.1-8.8)$ & 0.0 & \\
\hline 2 & 5 & 0 & $2.3(1.9-2.7)$ & 0.0 & \\
\hline \multicolumn{6}{|l|}{ Metastasis } \\
\hline Locally advanced & 4 & 1 & $5.2(2.0-8.4)$ & 25.0 & \multirow[t]{2}{*}{0.547} \\
\hline Metastatic & 27 & 3 & $4.9(2.5-7.3)$ & 11.1 & \\
\hline \multicolumn{6}{|l|}{ Line of therapy } \\
\hline First line & 22 & 3 & $5.0(4.1-5.9)$ & 18.2 & \multirow[t]{2}{*}{0.603} \\
\hline$\geq$ Second line & 9 & 1 & $3.6(0.0-7.3)$ & 0.0 & \\
\hline
\end{tabular}




\section{Discussion}

The MTD for everolimus and capecitabine in combination with cetuximab (cetuximab $250 \mathrm{mg} / \mathrm{m}^{2}$ weekly) was already reached at the first dose level (everolimus $5 \mathrm{mg}$ daily, and capecitabine $600 \mathrm{mg} / \mathrm{m}^{2}$ BID). The DLTs were mucositis, rash and hand-foot syndrome. In the phase II part of this study the incidence of grade 3-4 hyperglycemia, a well known complication of everolimus, was considerable and seems even to be higher compared to studies with everolimus alone. Despite the relative low dose level of everolimus (5 mg) the incidence of severe mucositis (13\% grade 3-4) was still considerable and also seems to be higher compared to trials with everolimus monotherapy $(10 \mathrm{mg})$. In other studies using single agent everolimus the incidence of grade 3-4 mucositis was $1-7 \%$ [26, 27]. In our previous phase I study (Deenen et al.) with everolimus $10 \mathrm{mg}$ and capecitabine $500-1000 \mathrm{mg} / \mathrm{m}^{2}$, mucositis was not doselimiting, however grade 1-2 mucositis was present in 50\% of the patients [21]. Thus, the addition of cetuximab resulted in more toxicity and prevented dose escalations of everolimus and capecitabine to more optimal dosages [28]. Although the underlying mechanism is unclear, co- administration of three agents with overlapping toxicities may be an important explanation for the excessive mucosal and/or epidermal toxicities seen in this study. Because the study of Deenen et al. demonstrated no pharmacokinetic interactions between everolimus and capecitabine, and monoclonal antibodies do not interfere at pharmacokinetic level, the increased toxicity is probably caused by pharmacodynamic interaction between the three drugs.

The objective response rate was only $6.5 \%$ (CI 1.1-18.8) with an overall survival of 5 months. In the first line cohort the OS was also 5.0 months, which even seems to be slightly inferior in comparison with gemcitabine as first line treatment [2]. In preclinical studies with cell lines of non small cell lung, pancreatic, colon, and breast cancer combined inhibition of mTOR and EGFR resulted in a potentiation of anti cancer activity and resensitization of cell lines resistant to EGFR inhibitors [15-18, 29]. Despite these promising preclinical results, exploration of this strategy in pancreatic cancer patients in the present study was disappointing. Possible reasons for clinical resistance to this treatment combination are the following. Toxicity prevented the administration of everolimus at optimal dosages. Everolimus shows most effective mTOR inhibition at a dose of $10 \mathrm{mg}$, and capecitabine monotherapy showed the optimal efficacy at $1000-1250 \mathrm{mg} / \mathrm{m}^{2}$ (BID) $[28,30,31]$. Secondly, the desmoplastic nature of pancreatic cancer with a high fibrotic component and minimal vascularization might prevent an adequate drug penetration, especially a large molecule like the monoclonal antibody cetuximab. Another, in various cancer types well established, cause of resistance to
anti-EGFR treatment is KRAS mutation, predominantly present in pancreatic cancer cells, which accounts for constitutive signaling directly downstream of EGFR. However, inhibitors of EGFR still show efficacy in some KRAS mutated pancreatic cancer cell lines [32].

In conclusion, dose escalation of everolimus and capecitabine in the present triple drug schedule with cetuximab was not possible because of severe, especially epidermal and mucosal, toxicity. At the relative low everolimus and capecitabine dosages in the phase II part of this study the toxicity was still considerable, leading to dose interruptions and adaptations. Considering the toxicity, the response rate of $6.5 \%$, and median survival of 5 months in first line treated patients, this regimen does not deserve further exploration in pancreatic cancer patients.

Funding Merck provided cetuximab and Novartis provided everolimus.

Conflict of interest The authors declare that they have no conflict of interest.

Open Access This article is distributed under the terms of the Creative Commons Attribution License which permits any use, distribution, and reproduction in any medium, provided the original author(s) and the source are credited.

\section{References}

1. Jemal A, Siegel R, Xu J, Ward E (2010) Cancer statistics, 2010. CA Cancer J Clin 60:277-300

2. Burris HA III, Moore MJ, Andersen J, Green MR, Rothenberg ML, Modiano MR, Cripps MC, Portenoy RK, Storniolo AM, Tarassoff P, Nelson R, Dorr FA, Stephens CD, Von Hoff DD (1997) Improvements in survival and clinical benefit with gemcitabine as first-line therapy for patients with advanced pancreas cancer: a randomized trial. J Clin Oncol 15:2403-2413

3. Conroy T, Gavoille C, Adenis A (2011) Metastatic pancreatic cancer: old drugs, new paradigms. Curr Opin Oncol 23:390-395

4. Conroy T, Desseigne F, Ychou M, Bouche O, Guimbaud R, Becouarn Y, Adenis A, Raoul JL, Gourgou-Bourgade S, de la Fouchardiere C, Bennouna J, Bachet JB, Khemissa-Akouz F, Pere-Verge D, Delbaldo C, Assenat E, Chauffert B, Michel P, Montoto-Grillot C, Ducreux M (2011) FOLFIRINOX versus gemcitabine for metastatic pancreatic cancer. N Engl J Med 364:18171825

5. Asano T, Yao Y, Zhu J, Li D, Abbruzzese JL, Reddy SA (2004) The PI 3-kinase/Akt signaling pathway is activated due to aberrant Pten expression and targets transcription factors NF-kappaB and cMyc in pancreatic cancer cells. Oncogene 23:8571-8580

6. Hezel AF, Kimmelman AC, Stanger BZ, Bardeesy N, Depinho RA (2006) Genetics and biology of pancreatic ductal adenocarcinoma. Genes Dev 20:1218-1249

7. Moore MJ, Goldstein D, Hamm J, Figer A, Hecht JR, Gallinger S, Au HJ, Murawa P, Walde D, Wolff RA, Campos D, Lim R, Ding K, Clark G, Voskoglou-Nomikos T, Ptasynski M, Parulekar W 
(2007) Erlotinib plus gemcitabine compared with gemcitabine alone in patients with advanced pancreatic cancer: a phase III trial of the National Cancer Institute of Canada Clinical Trials Group. J Clin Oncol 25:1960-1966

8. Philip PA, Benedetti J, Corless CL, Wong R, O'Reilly EM, Flynn PJ, Rowland KM, Atkins JN, Mirtsching BC, Rivkin SE, Khorana AA, Goldman B, Fenoglio-Preiser CM, Abbruzzese JL, Blanke CD (2010) Phase III study comparing gemcitabine plus cetuximab versus gemcitabine in patients with advanced pancreatic adenocarcinoma: Southwest Oncology Group-directed intergroup trial S0205. J Clin Oncol 28:3605-3610

9. Ito D, Fujimoto K, Mori T, Kami K, Koizumi M, Toyoda E, Kawaguchi Y, Doi R (2006) In vivo antitumor effect of the mTOR inhibitor CCI-779 and gemcitabine in xenograft models of human pancreatic cancer. Int J Cancer 118:2337-2343

10. Wolpin BM, Hezel AF, Abrams T, Blaszkowsky LS, Meyerhardt JA, Chan JA, Enzinger PC, Allen B, Clark JW, Ryan DP, Fuchs CS (2009) Oral mTOR inhibitor everolimus in patients with gemcitabine-refractory metastatic pancreatic cancer. J Clin Oncol 27:193-198

11. Camp ER, Summy J, Bauer TW, Liu W, Gallick GE, Ellis LM (2005) Molecular mechanisms of resistance to therapies targeting the epidermal growth factor receptor. Clin Cancer Res 11:397-405

12. Sampaio C, Dance M, Montagner A, Edouard T, Malet N, Perret B, Yart A, Salles JP, Raynal P (2008) Signal Strength Dictates Phosphoinositide 3-Kinase Contribution to Ras/Extracellular Signal-Regulated Kinase 1 and 2 Activation via Differential Gab1/Shp2 Recruitment: Consequences for Resistance to Epidermal Growth Factor Receptor Inhibition. Mol Cell Biol 28:587-600

13. Blanke CD, Rankin C, Demetri GD, Ryan CW, von Mehren M, Benjamin RS, Raymond AK, Bramwell VH, Baker LH, Maki RG, Tanaka M, Hecht JR, Heinrich MC, Fletcher CD, Crowley JJ, Borden EC (2008) Phase III randomized, intergroup trial assessing imatinib mesylate at two dose levels in patients with unresectable or metastatic gastrointestinal stromal tumors expressing the kit receptor tyrosine kinase: S0033. J Clin Oncol 26:626-632

14. Shepherd FA, Rodrigues PJ, Ciuleanu T, Tan EH, Hirsh V, Thongprasert S, Campos D, Maoleekoonpiroj S, Smylie M, Martins R, van Kooten M, Dediu M, Findlay B, Tu D, Johnston D, Bezjak A, Clark G, Santabarbara P, Seymour L (2005) Erlotinib in previously treated nonsmall-cell lung cancer. N Engl J Med 353:123-132

15. Bianco R, Garofalo S, Rosa R, Damiano V, Gelardi T, Daniele G, Marciano R, Ciardiello F, Tortora G (2008) Inhibition of mTOR pathway by everolimus cooperates with EGFR inhibitors in human tumours sensitive and resistant to anti-EGFR drugs. Br J Cancer 98:923-930

16. Buck E, Eyzaguirre A, Brown E, Petti F, McCormack S, Haley JD, Iwata KK, Gibson NW, Griffin G (2006) Rapamycin synergizes with the epidermal growth factor receptor inhibitor erlotinib in non-small-cell lung, pancreatic, colon, and breast tumors. Mol Cancer Ther 5:2676-2684

17. Goudar RK, Shi Q, Hjelmeland MD, Keir ST, McLendon RE, Wikstrand CJ, Reese ED, Conrad CA, Traxler P, Lane HA, Reardon DA, Cavenee WK, Wang XF, Bigner DD, Friedman HS, Rich JN (2005) Combination therapy of inhibitors of epidermal growth factor receptor/vascular endothelial growth factor receptor 2 (AEE788) and the mammalian target of rapamycin (RAD001) offers improved glioblastoma tumor growth inhibition. Mol Cancer Ther 4:101-112

18. Jimeno A, Kulesza P, Wheelhouse J, Chan A, Zhang X, Kincaid E, Chen R, Clark DP, Forastiere A, Hidalgo M (2007) Dual EGFR and mTOR targeting in squamous cell carcinoma models, and development of early markers of efficacy. Br J Cancer 96:952-959

19. La MS, Galetti M, Alfieri RR, Cavazzoni A, Ardizzoni A, Tiseo M, Capelletti M, Goldoni M, Tagliaferri S, Mutti A, Fumarola C,
Bonelli M, Generali D, Petronini PG (2009) Everolimus restores gefitinib sensitivity in resistant non-small cell lung cancer cell lines. Biochem Pharmacol 78:460-468

20. Nakachi I, Naoki K, Soejima K, Kawada I, Watanabe H, Yasuda H, Nakayama S, Yoda S, Satomi R, Ikemura S, Terai H, Sato T, Ishizaka A (2010) The combination of multiple receptor tyrosine kinase inhibitor and mammalian target of rapamycin inhibitor overcomes erlotinib resistance in lung cancer cell lines through c-Met inhibition. Mol Canc Res 8:1142-1151

21. Deenen MJ, Klumpen HJ, Richel DJ, Sparidans RW, Weterman MJ, Beijnen JH, Schellens JH, Wilmink JW (2011) Phase I and pharmacokinetic study of capecitabine and the oral mTOR inhibitor everolimus in patients with advanced solid malignancies. Investigational New Drugs. doi:10.1007/s10637-011-9723-4

22. Pacey S, Rea D, Steven N, Brock C, Knowlton N, Shand N, Hazell K, Zoellner U, O'Donnell A, Judson I (2004) Results of a phase 1 clinical trial investigating a combination of the oral mTORinhibitor Everolimus (E, RAD001) and Gemcitabine (GEM) in patients (pts) with advanced cancers. J Clin Oncol, 2004 ASCO Annual Meeting Proceedings (Post-Meeting Edition) 22(No 14S (July 15 Supplement)):3120

23. Li J, Zhao M, He P, Hidalgo M, Baker SD (2007) Differential metabolism of gefitinib and erlotinib by human cytochrome P450 enzymes. Clin Cancer Res 13:3731-3737

24. Bullock KE, Petros WP, Younis I, Uronis HE, Morse MA, Blobe GC, Zafar SY, Gockerman JP, Lager JJ, Truax R, Meadows KL, Howard LA, O’Neill MM, Broadwater G, Hurwitz HI, Bendell JC (2011) A phase I study of bevacizumab (B) in combination with everolimus (E) and erlotinib (E) in advanced cancer (BEE). Cancer Chemother Pharmacol 67:465-474

25. Le TC, Lee JJ, Siu LL (2009) Dose escalation methods in phase I cancer clinical trials. J Natl Canc Inst 101:708-720

26. Motzer RJ, Escudier B, Oudard S, Hutson TE, Porta C, Bracarda S, Grunwald V, Thompson JA, Figlin RA, Hollaender N, Urbanowitz G, Berg WJ, Kay A, Lebwohl D, Ravaud A (2008) Efficacy of everolimus in advanced renal cell carcinoma: a double-blind, randomised, placebo-controlled phase III trial. Lancet 372:449-456

27. Yao JC, Shah MH, Ito T, Bohas CL, Wolin EM, Van CE, Hobday TJ, Okusaka T, Capdevila J, de Vries EG, Tomassetti P, Pavel ME, Hoosen S, Haas T, Lincy J, Lebwohl D, Oberg K (2011) Everolimus for advanced pancreatic neuroendocrine tumors. N Engl J Med 364:514-523

28. Cartwright TH, Cohn A, Varkey JA, Chen YM, Szatrowski TP, Cox JV, Schulz JJ (2002) Phase II study of oral capecitabine in patients with advanced or metastatic pancreatic cancer. J Clin Oncol 20:160-164

29. Johnson BE, Jackman D, Janne PA (2007) Rationale for a Phase I Trial of Erlotinib and the Mammalian Target of Rapamycin Inhibitor Everolimus (RAD001) for Patients with Relapsed Non Small Cell Lung Cancer. Clin Cancer Res $13: 4628 \mathrm{~s}-4631$

30. Tabernero J, Rojo F, Calvo E, Burris H, Judson I, Hazell K, Martinelli E, Cajal S, Jones S, Vidal L, Shand N, Macarulla T, Ramos FJ, Dimitrijevic S, Zoellner U, Tang P, Stumm M, Lane HA, Lebwohl D, Baselga J (2008) Dose- and schedule-dependent inhibition of the mammalian target of rapamycin pathway with everolimus: a phase I tumor pharmacodynamic study in patients with advanced solid tumors. J Clin Oncol 26:1603-1610

31. Klumpen HJ, Beijnen JH, Gurney H, Schellens JH (2010) Inhibitors of mTOR. Oncologist 15:1262-1269

32. Bruns CJ, Solorzano CC, Harbison MT, Ozawa S, Tsan R, Fan D, Abbruzzese J, Traxler P, Buchdunger E, Radinsky R, Fidler IJ (2000) Blockade of the epidermal growth factor receptor signaling by a novel tyrosine kinase inhibitor leads to apoptosis of endothelial cells and therapy of human pancreatic carcinoma. Cancer Res 60:2926-293 